\title{
Effects of salinity on microbialite-associated production in Great Salt Lake, Utah
}

\author{
Melody R. Lindsay, ${ }^{1}$ Rachel E. Johnston, ${ }^{1}$ Bonnie K. Baxter, ${ }^{2}$ and Eric S. Boyd ${ }^{1,3}$ \\ ${ }^{1}$ Department of Microbiology and Immunology, Montana State University, Bozeman, Montana 59717 USA \\ ${ }^{2}$ Great Salt Lake Institute and Department of Biology, Westminster College, Salt Lake City, Utah 84105 USA
}

Citation: Lindsay, M. R., R. E. Johnston, B. K Baxter, and E. S. Boyd. 2019. Effects of salinity on microbialite-associated production in Great Salt Lake, Utah. Ecology 100(3):e02611. 10.1002/ecy.2611

Abstract. Microbialites, organosedimentary carbonate structures, cover approximately $20 \%$ of the basin floor in the south arm of Great Salt Lake, which ranges from $\sim 12$ to $15 \%$ salinity. Photosynthetic microbial mats associated with these benthic mounds contribute biomass that supports secondary production in the ecosystem, including that of the brine shrimp, Artemia franciscana. However, the effects of predicted increases in the salinity of the lake on the productivity and composition of these mats and on $A$. franciscana fecundity is not well documented. In the present study, we applied molecular and microcosm-based approaches to investigate the effects of changing salinity on (1) the primary productivity, abundance, and composition of microbialite-associated mats of GSL, and (2) the fecundity and survivability of the secondary consumer, $A$. franciscana. When compared to microcosms incubated closest to the in situ measured salinity of $15.6 \%$, the abundance of $16 \mathrm{~S}$ rRNA gene templates increased in microcosms with lower salinities and decreased in those with higher salinities following a 7 -week incubation period. The abundance of $16 \mathrm{~S}$ rRNA gene sequences affiliated with dominant primary producers, including the cyanobacterium Euhalothece and the diatom Navicula, increased in microcosms incubated at decreased salinity, but decreased in microcosms incubated at increased salinity. Increased salinity also decreased the rate of primary production in microcosm assays containing mats incubated for 7 weeks and decreased the number of $A$. franciscana cysts that hatched and survived. These results indicate that an increase in the salinity of GSL is likely to have a negative impact on the productivity of microbialite communities and the fecundity and survivability of $A$. franciscana. These observations suggest that a sustained increase in the salinity of GSL and the effects this has on primary and secondary production could have an upward and negative cascading effect on higher-trophic-level ecological compartments that depend on $A$. franciscana as a food source, including a number of species of migratory birds.

Key words: Artemia; brine shrimp; food web; Great Salt Lake; microbialite; primary production; salinity; secondary production.

\section{INTRODUCTION}

Primary producers form the base of food webs and play a central role in dictating energy flow to secondary consumers (Lindeman 1942). Thus, the overall health and stability of an ecosystem is often tied to the activity and stability of primary producers (Thompson et al. 2012). As such, any change to the physical, chemical, and/or biological attributes that define the habitat of primary producers is likely to influence the functioning of the entire ecosystem in what has been referred to as a trophic cascade (Paine 1980). Although this term is often reserved for describing the effects of predators and their

Manuscript received 3 October 2018; revised 19 November 2018; accepted 20 December 2018. Corresponding Editor: Joseph B. Yavitt.

${ }^{3}$ Corresponding Author. E-mail: eboyd@montana.edu downward-propagating effects thorough food webs across multiple trophic levels (Ripple et al. 2016), it has also been used to describe bottom-up controls on the food web (Terborgh et al. 2006).

Great Salt Lake (GSL) is the largest lake in the western United States and the eighth largest terminal lake in the world with a total surface area of $\sim 6,000 \mathrm{~km}^{2}$ (which varies widely seasonally) and a total catchment area of $\sim 52,000 \mathrm{~km}^{2}$ (Hassibe and Keck 1991). In 1959, a rock and gravel railroad causeway was constructed that segregated GSL into a north arm (NA) and south arm (SA). The causeway restricted the flow of water between these two arms, which created an artificial salinity gradient (Madison 1970, Cannon and Cannon 2002). Freshwater input into GSL via three primary rivers (the Bear, Jordan, and Weber rivers), all of which flow into the SA (Jones et al. 2009, Naftz et al. 2011), results in salinities that range from saturation in the NA $(270-300 \mathrm{~g} / \mathrm{L}$, 
$\sim 24-31 \%)$ to lower salinities in the SA $(140-150 \mathrm{~g} / \mathrm{L}$, $\sim 11-14 \%$; Chidsey et al. 2015, Lindsay et al. 2017).

The SA of GSL is highly productive, partially because of shallow margins (Fig. 1A) that are conducive to sunlight penetration throughout the water column (Vadeboncoeur et al. 2003, Wurtsbaugh 2009) and salinity values that are within the range tolerated by the dominant primary producer in the lake, Euhalothece (Lindsay et al. 2017). Euhalothece is a dominant component of the phytoplankton as well as benthic periphyton, the latter of which include mat communities associated with organo-carbonate structures, termed microbialites (Wurtsbaugh et al. 2011, Lindsay et al. 2017). Microbialites cover approximately $1,000 \mathrm{~km}^{2}(\sim 20 \%)$ of the lake bottom (Eardley 1938, Baskin 2014) across GSL, yet contribute a disproportionately large amount of primary production (Wurtsbaugh et al. 2011). For example, microbialite-associated periphyton communities have been estimated to contribute $\sim 50 \%$ of the total lake primary production (Wurtsbaugh et al. 2011).

The lake periphyton and phytoplankton biomass supports a limited number of lower-trophic-level secondary consumers in GSL, including the brine fly, Ephydra gracilis, and the brine shrimp, Artemia franciscana (Ephydra and Artemia, respectively; Stephens 1990, Wurtsbaugh et al. 2011). In addition to supplying nutrients, microbialites are also important for the regeneration of Ephydra species, as the larvae utilize the carbonate structure to complete a key step in their early life cycle by physically attaching to submerged microbialites in order to grow a pupal case and begin transforming into adults (Collins 1979). Ephydra represent a key food source supporting not only the $\sim 1.4$ million shorebirds that visit GSL annually (Wurtsbaugh 2009, Western Hemisphere Shorebird Reserve Network [WHSRN] 2018), but also other waterbirds that dive and eat Ephydra larvae (Roberts 2013). Artemia are also a source of food for waterbirds, and, together with the Ephydra, support more than 10 million individual birds across 250 different species annually (Aldrich and Paul 2002, Roberts 2013). Production and harvesting of Artemia cysts are also key contributors to the local economy. It is estimated that $\sim 35-45 \%$ of the world's total Artemia cyst production for aquaculture takes place in GSL, contributing an estimated maximum of $\$ 57$ million dollars to the local economy as of January 2012 (Belovsky et al. 2011, Great Salt Lake Advisory Council 2012, Wotipka 2014).

The shallow depth of much of the SA of GSL (average depth of $\sim 5 \mathrm{~m}$; Fig. 1A) makes it particularly susceptible
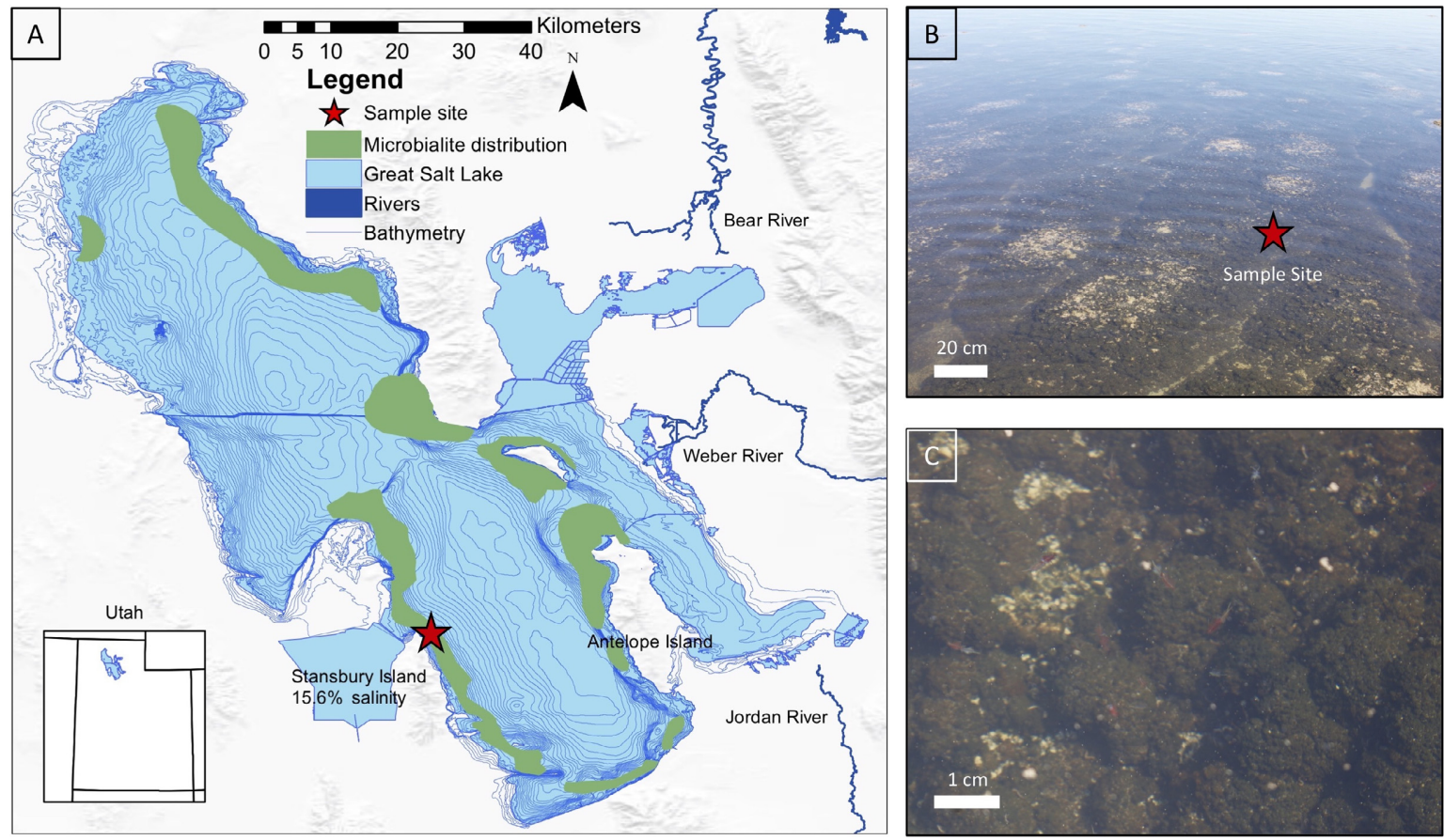

FIG. 1. (A) Map of Great Salt Lake constructed with lake, bathymetry, river, salinity, microbialite, and shaded relief reference layers. Microbialite reference layers modified from Eardley (1938). Shaded relief reference layer sourced from the U.S. Geological Survey (USGS) National Map: 3D Elevation Program. River and lake data modified from the National Hydrological Dataset (USGS, Environmental Protection Agency, State of Utah). Bathymetry modified from Tarboton (2017). The salinity value for the sampling site on Stansbury Island was determined as a part of this study conducted in August 2016. The location where samples were collected is indicated by a star. (B) South Arm (SA) microbialites near Stansbury Island, with the star indicating where the samples used in this study were collected. Microbialite structures are raised mounds with channels dividing them. (C) Close-up image of Stansbury Island microbialites reveals their vesicular texture as well as numerous Artemia (pink and white brine shrimp). Images in panels (B) and (C) were taken on 16 August 2018. 
to changes in lake level and volume, which in turn can impact salinity (Jones et al. 2009, Belovsky et al. 2011). Seasonal cycles affect short-term lake levels and salinities in GSL, as well as the macrobiota of GSL (Belovsky et al. 2011); however, historical models indicate that the average lake level and salinity as impacted by any seasonal cycling have been relatively stable annually over the past 100-200 yr. This indicates that climate change is not entirely responsible for recent changes in lake elevation and salinity (Wurtsbaugh et al. 2017). Rather, increasing consumptive water use over the past $140 \mathrm{yr}$ (39\% of river flow input is now diverted) has been implicated as the primary driver in the decrease in lake elevation by $3.6 \mathrm{~m}$, which also represents a decrease in volumetric percentage of $48 \%$ and a decrease in surface area of $50 \%$. This decrease in lake level has led to increased salinity in the SA of GSL over historical values.

Variations in salinity have been shown to impact the aquatic biological community in GSL, with the effects on secondary consumers Artemia and Ephydra being fairly well documented (Stephens 1990). However, it is not as clear how these effects correlate with changes in the composition and abundance of primary producers. For example, in a microcosm setting, the abundances of eukaryotic species were shown to be negatively impacted by increases in salinity. Artemia biomass decreased by $60 \%$ as salinity increased from $\sim 7.2$ to $\sim 19.5 \%$ (75$225 \mathrm{~g} / \mathrm{L}$ ), and Ephydra biomass decreased by $45 \%$ as salinity increased from $\sim 4.9$ to $\sim 21.4 \%(50-250 \mathrm{~g} / \mathrm{L}$; Barnes and Wurtsbaugh 2015). Likewise, an increase in salinity not dependent on regular seasonal changes between 1960 and 1963 was shown to result in a decrease in the number of species and the amount of phytoplankton in the SA, and this was correlated with a decrease in the abundance of Artemia adults (Stephens 1998). In contrast, an increase in lake elevation between 1982 and 1987 was associated with a decrease in salinity to $6 \%$, which resulted in changing phytoplankton communities. Specifically, communities dominated by obligate halophiles transitioned to those dominated by phototrophs (Stephens 1990). However, this transition was associated with a decrease in the number of Artemia adults, which was suggested to be due to cysts sinking to the bottom of the lake where they could not hatch (Stephens 1990, 1998), or top-down control by a predaceous insect that invaded at the lower salinities (Wurtsbaugh 1992). A recent analysis of plankton and microbialite-associated periphyton mats collected from the SA (11.8\% salinity) and the NA (31.4\% salinity) revealed that photosynthetic microbial species (the diatom Navicula and cyanobacterium Euhalothece) were abundant components of the plankton and periphyton mats in the SA but not in the NA (Lindsay et al. 2017). This suggested that the elevated salinity in the NA resulting from construction of the causeway and restricted input of freshwater had a negative effect on these primary producers and this may have an effect on secondary consumers such as
Artemia. However, the salinity level that is intermediate to those measured in the SA and the NA and where the abundance and activity of phototrophic populations begins to be affected is not known.

In this study, we hypothesized that changing salinities impact the abundance, composition, and activity of periphyton microbial mat communities, which in turn affect the fecundity of secondary consumers dependent on these mats as a food source and for maturation. To investigate these interrelated hypotheses, we conducted a microcosm incubation containing GSL lake water, SA microbial mats, and Artemia cysts and artificially decreased or increased salinity. Over a 7-week period, changes in 16S rRNA gene abundance (proxy for microbial biomass) and composition were determined. The number of Artemia cysts that hatched and that survived were quantified over this incubation period as an indicator of secondary production. Finally, rates of primary production were determined in microbial mats at the end of the 7-week incubation using a microcosm approach. Results are discussed in the context of the threshold salinities where primary production is most likely to be affected and where an upward, negative cascading effect on higher trophic compartments might be expected.

\section{Materials And Methods}

\section{Description of sample site and sample collection}

Microbialite subsamples were collected on 16 August 2016 in the SA of GSL just offshore of the northern tip of Stansbury Island $\left(40^{\circ} 55^{\prime} 02.3^{\prime \prime} \mathrm{N}, 112^{\circ} 29^{\prime} 28.0^{\prime \prime} \mathrm{W}\right)$ in shallow waters at a depth of $10 \mathrm{~cm}$ (Fig. 1). At the time of sampling ( 2:00 p.m.), the water above the microbialites had a temperature of $25.2^{\circ} \mathrm{C}$, a $\mathrm{pH}$ of 8.12 , and a salinity of $15.6 \%$. Subsamples of microbialite mats ( $250 \mathrm{~g})$ were collected with an ethanol-sterilized spoon and placed in sterile 50-mL tubes for transport back to the laboratory. In the laboratory, mats were maintained at salinities measured in the field in tanks with water levels monitored and adjusted every $3 \mathrm{~d}$ for a period of 9 mo prior to the setup of microcosms. Importantly, and as described in detail below, the composition of the mats determined at time 0 of the incubation period and those recovered directly from the SA of GSL previously (Lindsay et al. 2017) were nearly identical. Water from GSL was collected in a 40-L bucket from the SA in May of 2017. The salinity of the water at the time of collection was $8.0 \%$.

\section{Microcosm setup}

Triplicate microcosms were prepared at six salinities including $8,10,15,20,25$, and $30 \%$ in autoclaved glass jars. One hundred fifty milliliters of filtered $(0.22 \mu \mathrm{m})$ water from the SA was placed in autoclaved glass jars (300-mL capacity, $5-\mathrm{cm}$ diameter by $13-\mathrm{cm}$ height). Because GSL is primarily a $\mathrm{NaCl}$ lake (Oren 2013), the 
salinity of microcosms was artificially adjusted with $\mathrm{NaCl}$. Salinities were verified using an AR200 digital refractometer (Reichert Inc., Depew, New York, USA). Ten grams of homogenized photosynthetic mat were added to each microcosm, followed by addition of $0.5 \mathrm{~g}$ of Artemia cysts ( $\sim 50,000$ cysts total) originally sourced from GSL (Aquatic Foods, California Blackworm Co., Fresno, California, USA). Microcosms were incubated in full south-facing sunlight in the lab at Montana State University starting on 19 October 2017. All treatments were incubated under the same conditions in the same window to minimize variation among microcosms. To facilitate gas exchange and minimize input of exogenous material, microcosms were covered with autoclaved cheese cloth. Water and salinity levels were maintained daily for the incubation period by the addition of MilliQ water (Millipore Sigma, Burlington, Massachusetts, USA). Microcosms and their contents were stirred daily at the time of water addition to mix their contents.

\section{$D N A$ extraction, polymerase chain reaction ( $P C R)$, and quantitative PCR ( $q P C R$ )}

Microbial mat material was sampled from triplicate microcosms by stirring the microcosms and removing $1 \mathrm{~mL}$ of combined benthic mat and planktonic material. DNA was extracted from this microbial mat suspension using the FastDNA Spin Kit for Soil (MP Biomedicals, Santa Ana, California, USA) at 0, 4, and 7 weeks of incubation, according to previously published protocols (Hamilton et al. 2013). The concentration of DNA in each extract was determined with the Qubit dsDNA HS Assay kit (Molecular Probes, Waltham, Massachusetts, USA). Genomic DNA was subjected to PCR amplification of small subunit rRNA genes using the PCR primers 515F (5'-GTGCCAGCMGCCGCGGTAA-3') and 806R (5'-GGACTACHVGGGTWTCTAAT-3'). Thirtyfive cycles of PCR were conducted as previously described (Colman et al. 2016) at an annealing temperature of $55^{\circ} \mathrm{C}$. Quantitative PCR (qPCR) of $16 \mathrm{~S}$ rRNA genes was performed on DNA extracts using the same primers (515F-806R) and the SsoAdvanced Universal SYBR Green Supermix (Bio-Rad Laboratories, Hercules, California, USA) using previously described methods (Lindsay et al. 2018). Plasmid standards for use in relating copy numbers of templates to threshold amplification signals were prepared as described previously (Boyd et al. 2011). Negative control reactions were performed in the absence of added DNA.

\section{Sequencing and analysis of $16 S \mathrm{r} R \mathrm{NA}$ genes}

16S rRNA gene amplicons were sequenced using multiplexed, paired-end Illumina MiSeq tag sequencing by MrDNA (Shallowater, Texas, USA) and were barcoded as previously described (Dowd et al. 2008). Postsequence processing was performed with Mothur (ver. 1.40.3; Schloss et al. 2009) as previously described
(Hamilton et al. 2013). Briefly, raw libraries were trimmed to a minimum length of 250 bases and were subjected to a filtering step using the quality scores file to remove sequences, using previously described methods (Lindsay et al. 2017). Unique sequences were aligned using domain-specific SILVA databases, and sequences were trimmed using a defined start and end site based on inclusion of $80 \%$ of the total sequences. The resulting unique sequences were preclustered to remove errors, and chimeras were identified and removed using UCHIME (Edgar et al. 2011). Operational taxonomic units (OTUs) were assigned at a sequence similarity of 0.97 using the opticlust method. The remaining sequences were randomly subsampled to normalize the total number of sequences in each library to 22,139 . Rarefaction curves were used to compute the percentage of coverage of the predicted taxonomic richness for each library. Sequences were classified with the RDP database using the Bayesian classifier (Wang et al. 2007). Raw reads, quality scores, and mapping files for the gene libraries have been deposited in the NCBI short reads archive under BioProject number PRJNA492463.

Absolute abundances of each OTU were calculated by multiplying the relative abundance of each OTU in each library by the abundance of $16 \mathrm{~S}$ rRNA genes in that sample, as determined via qPCR. The percentage of change in absolute abundances at each salinity and at each time point was normalized to absolute abundances in microcosms incubated at specified salinities as determined at week 0 .

\section{Dissolved inorganic carbon assimilation assays}

Rates of dissolved inorganic carbon (DIC) assimilation in microbial mats sampled following 7 weeks' incubation in microcosms were assessed as previously described (Boyd et al. 2009, 2012). Briefly, at the end of 7 weeks of incubation, $10-\mathrm{mL}$ subsamples of homogenized microbial mat and planktonic cells were collected from each microcosm with a $10-\mathrm{mL}$ syringe. These samples were then added to sterile 24-mL serum bottles, and these were capped with butyl rubber stoppers. Killed controls were prepared by autoclaving for $30 \mathrm{~min}$ at $121^{\circ} \mathrm{C}$. Biological and abiological assays were prepared in triplicate. Autoclaved assays were incubated at room temperature for $24 \mathrm{~h}$ and then were subjected to an additional autoclave cycle of $30 \mathrm{~min}$ at $121^{\circ} \mathrm{C}$. The microcosm assays were initiated by injection of $1.0 \mu \mathrm{Ci}$ of sterile $\left[{ }^{14} \mathrm{C}\right]$ sodium bicarbonate $\left(\mathrm{NaH}^{14} \mathrm{CO}_{3}\right)$ to each serum bottle to achieve a final concentration of $2.0 \mu \mathrm{mol} / \mathrm{L} \mathrm{NaH}^{14} \mathrm{CO}_{3}$. All microcosms were incubated in direct sunlight for $30 \mathrm{~min}$. Assays were terminated by freezing at $-80^{\circ} \mathrm{C}$ and were stored at $-20^{\circ} \mathrm{C}$ until processing.

Sealed serum bottles and their contents were thawed at room temperature for $1 \mathrm{~h}$ and were acidified to a $\mathrm{pH}$ of $<2$ by injection of $1 \mathrm{~N}$ hydrochloric acid to volatilize unreacted DIC and carbonates. After acidification, the bottles were unsealed and allowed to de-gas as 
previously described (Urschel et al. 2015). Microcosm contents were filtered onto $0.22-\mu \mathrm{m}$ preweighed polycarbonate membranes, washed, and dried overnight at $80^{\circ} \mathrm{C}$. Dried filters and contents were weighed to facilitate normalization of DIC assimilation to grams dry mass $(\mathrm{gdm})$ of added microcosm material. Filters and associated material were placed in scintillation vials and were overlaid with $10 \mathrm{~mL}$ of CytoScint ES liquid scintillation fluid. The radioactivity measured in counts per minute (CPM) was measured on a Beckman LS 6500 liquid scintillation counter (Beckman Coulter, Inc., Indianapolis, Indiana, USA) and converted to disintegrations per minute (DPM) and to rates of $\mathrm{CO}_{2}$ uptake, according to previously published protocols (Urschel et al. 2015, Lindsay et al. 2018). DPMs measured in killed controls were subtracted from experimental microcosms, and the average and standard error of the mean of three replicate assays for each microcosm at each salinity are presented (a total of nine assays for each salinity).

\section{Determination of Artemia viability}

Digital photographs of each triplicate microcosm at each salinity were taken daily to determine the number of Artemia that had hatched at any given time during the microcosm incubation and their survival. Individual Artemia were counted daily, and weekly average numbers of daily Artemia counts for each salinity are presented.

\section{RESUlTS}

\section{Abundance of 16S rRNA genes}

Quantitative PCR (qPCR) of community 16S rRNA genes was used as a proxy for total microbial biomass and, as such, to determine the effects of changing salinity on the abundance of biomass in microcosms during the incubation period (Fig. 2). The abundance of 16S rRNA genes increased by $152 \%$ over a 4 -week incubation period at a salinity $(15 \%)$ close to that of waters overlying microbialite-associated mats at the time that they were collected $(15.6 \%)$. Following another 3 weeks of incubation, the abundance of genes decreased slightly from levels observed at the 4-week incubation point, but was still $128 \%$ greater than gene abundances at week 0 . A decrease in the salinity to 10 and $8 \%$ resulted in large overall increases (179 and 161\% increases, respectively) in the abundance of $16 \mathrm{~S}$ rRNA genes following 4 weeks' incubation. Following an additional 3 weeks' incubation, the abundance of 16S rRNA genes in microcosms incubated at $10 \%$ salinity increased further to $537 \%$ of gene abundances at week 0 , whereas abundances at $8 \%$ salinity decreased further from levels observed at the 4-week incubation point. Thus, the largest increase in template abundance in microcosms was observed at $10 \%$ salinity, which is slightly less than the $15.6 \%$ salinity at the time the phototrophic mat communities were collected.
In contrast to decreased salinities that resulted in a net increase in 16S rRNA gene abundances, incubation of microcosms at elevated salinities resulted in an overall net decrease in $16 \mathrm{~S}$ rRNA gene abundance. Incubation of microbialite-associated mats at $20 \%$ salinity for 4 weeks resulted in a $24 \%$ decrease in the abundance of $16 \mathrm{~S}$ rRNA genes when compared to abundances at week 0 . Following another 3 weeks of incubation, the abundances decreased further to $43 \%$ less than abundances of genes at week 0 . Gene abundances at the highest tested salinities of 25 and 30\% salinity after 4 weeks' incubation decreased by 96 and $95 \%$ when compared to abundances at week 0 . Following another 3 weeks of incubation at these salinities, the abundances of 16S rRNA genes were 97 and $84 \%$ lower than those at week 0 , respectively.

\section{Microbialite community taxonomic diversity and composition}

A total of 22,139 16S rRNA gene sequences were subsampled from microbialite-associated communities in each of the microcosms at each specified salinity, resulting in estimated coverages of $\sim 60-70 \%$ of the predicted diversity (Appendix S1: Table S1). A total of 14 abundant orders, classified here as those with sequences that comprised $>2 \%$ of total reads, were identified in communities sampled from all microcosms (Fig. 3). The most abundant 16S rRNA gene OTU from all salinities (maximally $46 \%$ at $25 \%$ salinity, week 0 ) was most closely related to the heterotroph Longibacter salinarum (99\% sequence identity) within the order Sphingobacteriales (Fig. 3, Appendix S1: Fig. S1), which grows optimally at $8-12 \%$ salinity (Xia et al. 2016). The second most abundant OTU from across all salinities (maximally $19.5 \%$ of total OTUs at $20 \%$ salinity, week 0 ) was most closely related $(100 \%$ sequence identity) to the obligate organic carbon fermenter Salinispira pacifica, previously isolated from a lithifying hypersaline microbial mat (Ben Hania et al. 2015). The most abundant putatively phototrophic OTU and third most abundant OTU overall (maximally $18.5 \%$ at $8 \%$ salinity, week 0 ) was most closely related (100\% sequence identity) to the halophilic cyanobacterium Euhalothece sp. MPI 96N304 within the order Chroococcales (Garcia-Pichel et al. 1998; Fig. 3, Appendix S1: Fig. S1). The most abundant 16S rRNA gene affiliated with a eukaryote (i.e., via chloroplast 16S rRNA gene) and the second most abundant OTU affiliated with a phototroph was most closely related $(89 \%$ sequence identity) to the alga Navicula ramosissima within the order Naviculales (Fig. 3, Appendix S1: Fig. S1; An et al. 2016). Importantly, the generally large size of Euhalothece and Navicula cells, relative to other heterotrophic cells identified here, suggests that these phototrophs contribute an even greater amount of biomass to the GSL mat communities than is suggested by the relative abundance of $16 \mathrm{~S}$ rRNA gene templates alone. 16S rRNA genes affiliated with Archaea were not detected in abundances $>2 \%$ in any microcosm. 


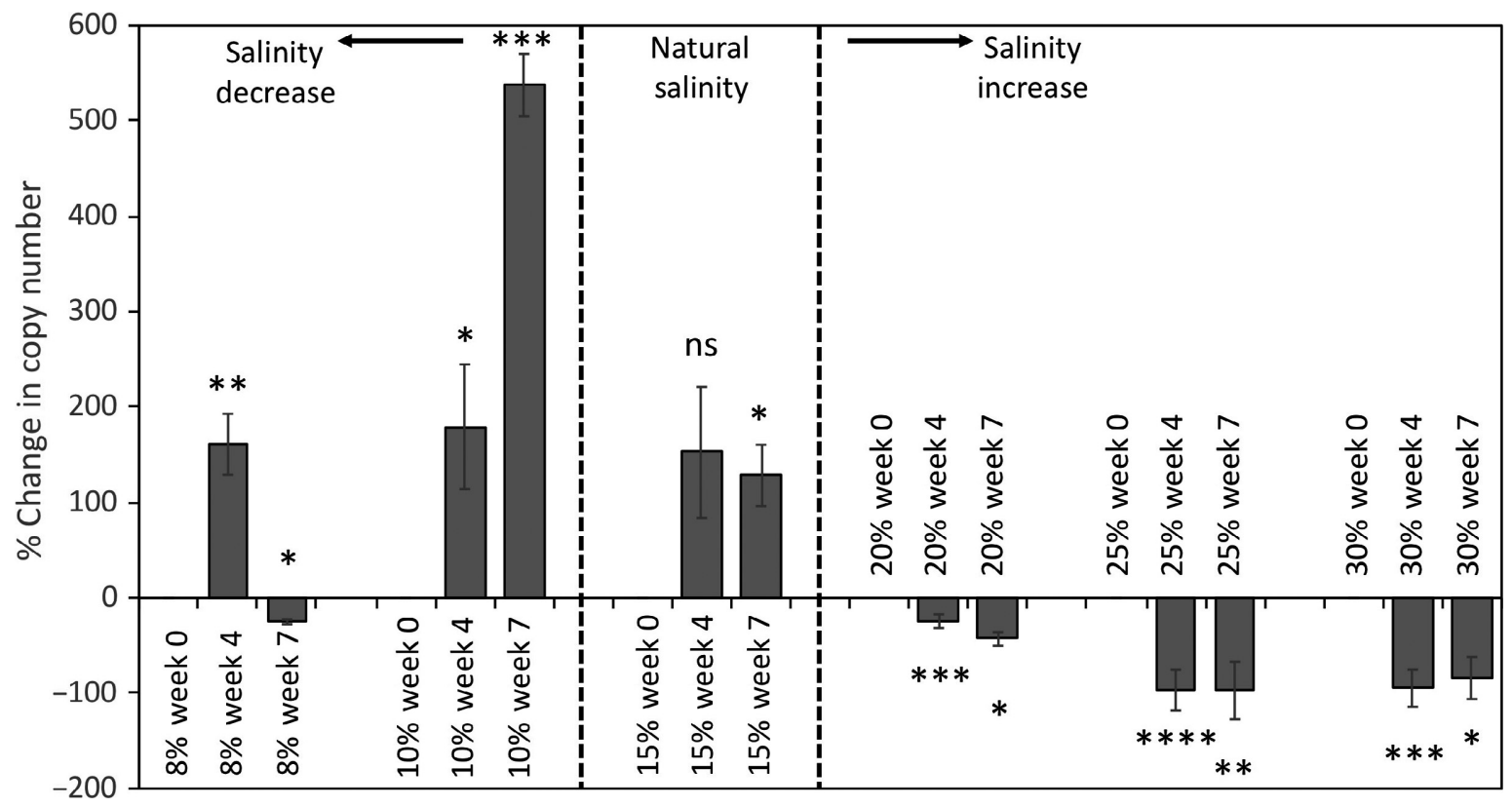

FIG. 2. Change in percentage of abundance of $16 \mathrm{~S}$ rRNA gene templates associated with microbialite mat communities sampled from microcosms incubated for specified durations at specified salinities. Template abundances at weeks 4 and 7 were normalized to template abundances determined for subsamples collected at week 0 of the incubation period for each salinity. Results are presented as the mean of triplicate qPCR assays with error bars representing the standard error of triplicates. The benthic microbialite mat samples used for these assays were collected from a location where the salinity of the overlying water column was $15.6 \%$, and these are depicted as "Natural salinity." Statistically significant differences between measurements made at 4 and 7 weeks' incubation and those made at 0 weeks' incubation are denoted by $* * * * P<0.0001,{ }^{* * *} P<0.001,{ }^{* *} P<0.01, * P<0.1$; ns, $P>0.1$; ns, not significant with a $P>0.1$.

\section{Microbialite community taxonomic diversity and composition: influence of incubation time}

The composition of communities inhabiting microcosms changed over the course of the incubations, regardless of salinity. The percentages of changes in the absolute abundance of templates reported here are relative to abundances determined at week 0 at the specified salinity. The composition of communities incubated at $15 \%$ salinity changed over the course of the 4 - or 7 -week incubation period. After only 4 weeks of incubation, the OTUs affiliated with the orders Spirochaetales and Desulfobacterales decreased in abundance relative to week 0 (decreases of 5 and $81 \%$, respectively), but all other OTUs exhibited increased template abundances.

At 7 weeks' incubation, the absolute abundance of OTUs affiliated with seven of the most abundant taxonomic orders decreased when compared to week 0 , including the Sphingobacteriales (25\% decrease), the Spirochaetales $(45 \%$ decrease), and the Desulfobacterales (87\% decrease) among several others (Fig. 3). In contrast, the absolute abundance of OTUs affiliated with the other seven most abundant taxonomic orders increased at 7 weeks of incubation relative to the 0 -week incubations, including those of the Chroococcales and the Naviculales (increases of 104 and 1,977\%, respectively). The absolute abundance of OTUs affiliated with other phototrophs, including the Chromatiales, Rhodobacterales, and Rhodospirillales, also increased by 131, 19, and $125 \%$, respectively, during the 7 -week incubation period at $15 \%$ salinity.

At lower salinities of 8 and $10 \%$, the absolute abundances of OTUs affiliated with the majority of the most prevalent taxonomic orders increased after both 4 and 7 weeks of incubation relative to week 0 abundances (Fig. 3). These included sequences belonging to the most abundant order, Sphingobacteriales, which exhibited increases in abundance at $8 \%$ (increases of 140 and $72 \%$ at 4 and 7 weeks, respectively) and 10\% salinity (increases of 70 and $262 \%$ ). Likewise, the absolute abundance of OTUs affiliated with the phototrophic order Naviculales increased by 669 and $233 \%$ at 4 and 7 weeks, respectively, when incubated at $8 \%$ salinity and increased by 1,889 and $3,811 \%$ at 4 and 7 weeks, respectively, when incubated at $10 \%$ salinity relative to their abundances at 0 weeks. The absolute abundance of Chromatialesaffiliated OTUs increased by 256 and $141 \%$ at 4 and 7 weeks, respectively, when incubated at $8 \%$ salinity, and increased by 139 and $162 \%$, respectively, when incubated at $10 \%$ salinity relative to their abundances at 0 weeks. Finally, the absolute abundance of OTUs belonging to the most abundant phototrophic order, Chroococcales, increased by $96 \%$ after 4 weeks' incubation and by $554 \%$ after 7 weeks' incubation at $10 \%$ salinity, but decreased 

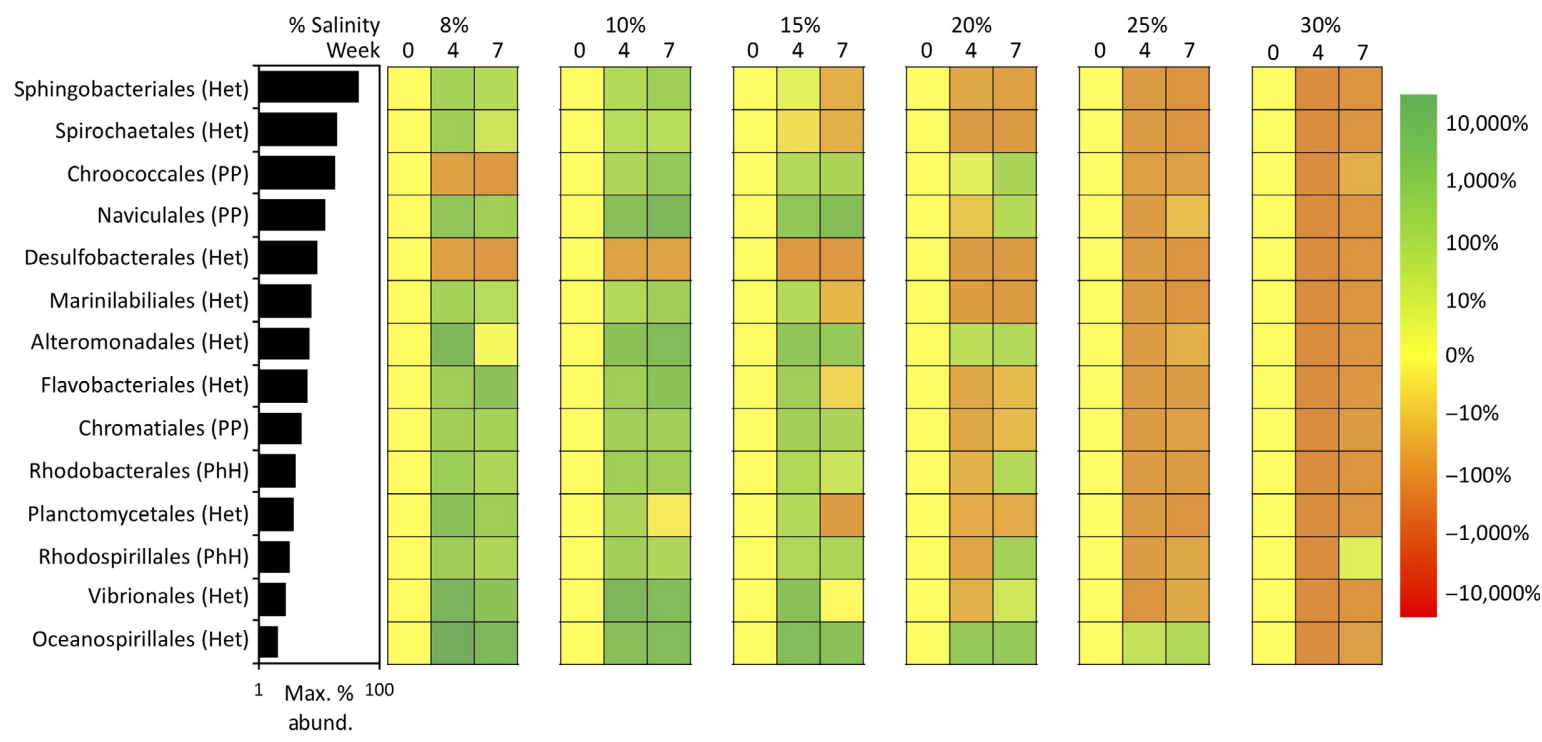

FIG. 3. Composition of $16 \mathrm{~S}$ rRNA gene OTUs (as represented by their closest cultivated representatives) recovered from microbialite communities in microcosms incubated at different salinities from 0,4 , and 7 weeks' incubation time. Representative OTUs were binned at the order level (specified on the $y$ axis), with only orders that represent $>2 \%$ of total sequences in a given sample included in the figure. Taxonomic bins are sorted according to their maximum relative abundance across all samples for each salinity. The rank abundance plot for all taxonomic bins is presented to the left of the figure with the maximum percentage of abundance expressed on a log scale. The color of each block corresponds to the percentage of relative change (see legend) in the abundance of sequences affiliated with each order at a specified salinity and time point (specified on the $x$ axis) as normalized to their abundance at week 0 for each salinity. Nonnormalized percentage of relative abundances of each order in all microcosms at each time point are depicted in Appendix S1: Fig. S1. Het, heterotrophic; Max. \% abund., maximum percentage of abundance; PhH, photoheterotroph; $\mathrm{PP}$, primary producer.

by 56 and $89 \%$ after 4 and 7 weeks' incubation, respectively, when incubated at $8 \%$ salinity. The only OTU to decrease in template abundance following 4 and 7 weeks' incubation at both $8 \%$ salinity (decreases of 41 and $84 \%$, respectively) and $10 \%$ salinity (decreases of 59 and $49 \%$, respectively) was most closely related $(96 \%$ sequence identity) to the sulfate-reducing bacterium Desulfobacula toluolica of the order Desulfobacterales (Rabus et al. 1993; Fig. 3).

At the elevated salinity of $20 \%$, OTUs affiliated with the majority of the most abundant orders (11 of 14) decreased in absolute abundance after 4 weeks of incubation relative to abundances at week 0 . However, the abundances of four of these OTUs then increased after an additional 3 weeks of incubation relative to week 0 abundances, including the phototrophic order Naviculales (decreased by $10 \%$ but then increased by $73 \%$; Fig. 3). Three of the most abundant orders increased after both 4 and 7 weeks of incubation, including sequences affiliated with the Chroococcales (increases of 5 and $113 \%$, respectively), Alteromonadales (increases of 32 and $66 \%$, respectively), and Oceanospirillales (increases of 472 and $443 \%$, respectively). At a salinity of $25 \%$, all orders decreased in abundance after both 4 and 7 weeks of incubation, except for Oceanospirillales, which increased by $22 \%$ at 4 weeks and by $80 \%$ after 7 weeks relative to abundances at 0 weeks. At $30 \%$ salinity, all orders exhibited a decrease of template abundances at week 4 , with only the order Rhodospirillales exhibiting a slight increase of $6 \%$ after another 3 weeks' incubation relative to abundances at week 0 .

\section{Microbial community taxonomic diversity and composition: influence of salinity}

The abundances of OTUs in microcosms incubated at decreased or increased salinity for 4 and 7 weeks were compared to community changes that occurred at the natural salinity of $15 \%$ after 4 and 7 weeks of incubation to identify the influence of salinity on community composition. After 4 weeks of incubation at the lowest salinity (8\%), all orders increased in abundance (Fig. 4). At $10 \%$ salinity and after 4 weeks of incubation, the abundance of all orders increased except for the orders Chroococcales, Marinilabiliales, and Flavobacteriales, which decreased by 57,21 , and $35 \%$, respectively. When the salinity was increased to 20,25 , or $30 \%$, nearly all OTUs decreased in abundance following 4 weeks' incubation, with the exception being sequences affiliated with the order Desulfobacterales, which increased by 39 and $22 \%$ at 20 and $25 \%$ salinity, respectively.

After another 3 weeks of incubation (7 weeks' incubation in total), further shifts in the composition of the communities were observed. In particular, sequences affiliated with the most abundant phototrophic order Chroococcales decreased by $17 \%$ at $8 \%$ salinity but 
increased by $12 \%$ at $10 \%$ salinity, relative to microcosms incubated at $15 \%$ for 7 weeks. A similar pattern was observed in the next most abundant phototrophic order Naviculales, which decreased by $68 \%$ at $8 \%$ salinity but increased by $19 \%$ at $10 \%$ salinity. The other most abundant orders increased in their abundance at lower salinities relative to microcosms incubated at $15 \%$ for 7 weeks, except for the order Desulfobacterales, which decreased by $13 \%$ at $8 \%$ salinity (but increased by $180 \%$ at $10 \%$ salinity), and the order Rhodospirillales, which decreased by 47 and $16 \%$ at salinities of 8 and $10 \%$, respectively.

After 7 weeks of incubation at the increased salinities of 20,25 , and $30 \%$, the abundance of $16 \mathrm{~S}$ rRNA genes affiliated with the majority of the most abundant orders decreased, including the orders of Sphingobacteriales (decreases of 23, 65, and 81\%, respectively) and Spirochaetales (decreases of 18, 70, and 73\%). The most abundant phototrophic order, Chroococcales, increased by $51 \%$ at $20 \%$ salinity, but then decreased by 64 and $36 \%$ at the higher salinities of 25 and $30 \%$, respectively, at 7 weeks' incubation relative to microcosms incubated at $15 \%$ salinity. The abundance of the order Desulfobacterales also increased at $20 \%$ salinity (by $64 \%$ ) but then decreased at 25 and $30 \%$ salinity by 41 and $55 \%$, respectively. Overall, the largest decrease in sequence abundance in microcosms incubated at elevated salinities was observed in the phototrophic order Naviculales, which decreased by 84,92 , and $99 \%$ at 20,25 , and $30 \%$ salinity, respectively.

\section{Primary production: DIC assimilation rate potentials}

Following 7 weeks of incubation, subsamples of microbial mat materials were collected from microcosms and subjected to quantification of DIC assimilation using a radiotracer microcosm-based approach. Assimilation of DIC was detected in microbialite-associated communities when incubated at all salinities (Fig. 5). At the salinity $(15 \%)$ corresponding closest to that of the SA of GSL at the time that the microbialite-associated mats were collected (15.6\%), the rate of DIC assimilation was $3.39 \mathrm{nmol} \mathrm{CO}_{2} \cdot \mathrm{h}^{-1} \cdot \mathrm{g}^{-1}$. Mats incubated at lower salinities of 8 and $10 \%$ exhibited rates of DIC assimilation that were $14.8 \%$ lower and $16.7 \%$ higher than the rate measured at $15 \%$ salinity (3.16 and $3.64 \mathrm{nmol}$ $\mathrm{CO}_{2} \cdot \mathrm{h}^{-1} \cdot \mathrm{g}^{-1}$, respectively), although these differences were not significantly different from that measured at $15 \%$ salinity $(P=0.10$ and 0.14 , respectively). At elevated salinities of 20,25 , and $30 \%$, the rates of DIC assimilation in microbialite-associated mats were 74,60 , and $58 \%$ lower $\left(2.50,2.02\right.$, and $1.97 \mathrm{nmol} \mathrm{CO} \mathrm{CO}_{2} \cdot \mathrm{h}^{-1} \cdot \mathrm{g}^{-1}$, respectively) than the rate measured in mats incubated at $15 \%$ salinity. These rates were significantly different from those measured at $15 \%$ salinity $(P<0.01$ for all three treatments).

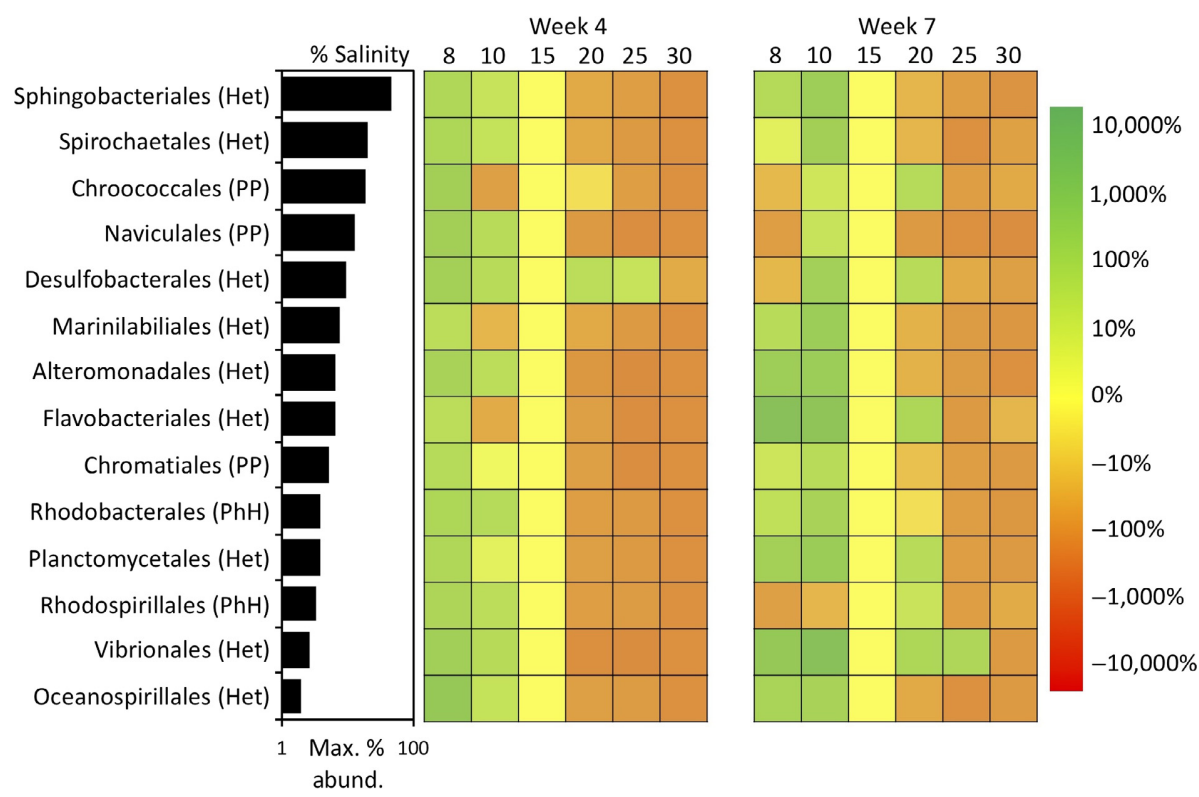

FIG. 4. Composition of 16S rRNA gene OTUs (as represented by their closest cultivated representatives) recovered from microbialite communities in microcosms incubated at different salinities from 0,4 , and 7 weeks' incubation time. Taxonomic bins are sorted and presented in the same way as Fig. 3, using the same rank abundance plot from Fig. 3. The color of each block corresponds to the percentage of relative change (see legend) in the abundance of sequences affiliated with each order at the sampling time points of 4 and 7 weeks for each salinity as normalized to the abundance of each order at 4 and 7 weeks at the natural salinity of $15 \%$. Nonnormalized percentages of relative abundances of each order in all microcosms at each time point are depicted in Appendix S1: Fig. S1. Het, heterotrophic; Max. \% abund., maximum percentage of abundance; PhH, photoheterotroph; PP, primary producer. 


\section{Secondary production: Artemia hatch and survival}

The number of Artemia cysts that hatched and the number of Artemia individuals that survived in experimental microcosms were low, regardless of the salinity of the microcosm (Fig. 6). Nonetheless, Artemia cysts hatched and survived in microcosms at salinities that ranged from 8 to $20 \%$. No juvenile or adult Artemia were observed in microcosms incubated at 25 and $30 \%$ salinity. The numbers of Artemia that hatched were highest in microcosms incubated at 8 and $10 \%$ salinity, with an average of 282 and 107 individuals observed at week 1, respectively. Artemia cysts inoculated into microcosms with salinities of 15 and $20 \%$ did not hatch until week 12, and an average of only 20 and 18 individual Artemia were observed, respectively. At the end of observation at week 16, the survivability of Artemia individuals (microcosms with salinities of $8-20 \%$ ) were similar, with a total of 11 individuals at $8 \%$ salinity and 15 individuals at $15 \%$ salinity.

\section{Discussion}

In the present study, a microcosm-based approach was used to examine the effects of changing salinity on the abundance, composition, and activity of microbialite-associated communities in GSL and to determine how these changes may affect the hatch rate and survivability of the secondary consumer Artemia. The primary goal of this study was to determine the microbial

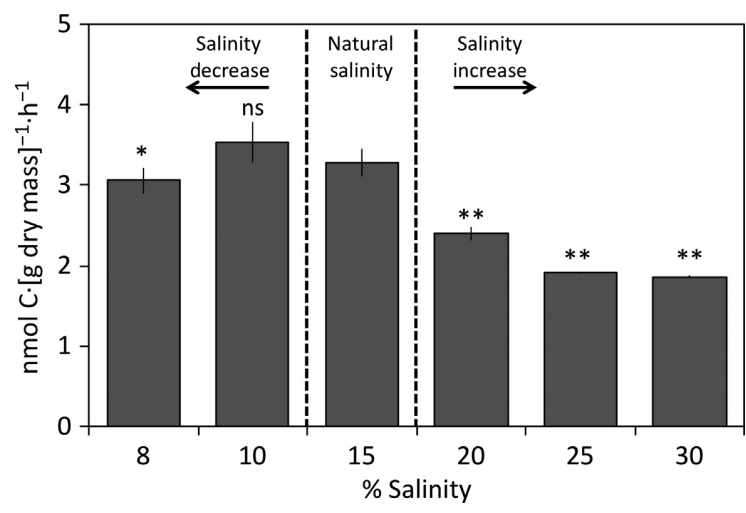

FIG. 5. Dissolved inorganic carbon (DIC) uptake in microbialite-associated mat communities sampled from microcosms. Following 7 weeks' incubation, subsamples of mat were transferred to microcosms and were incubated in the light for $30 \mathrm{~min}$ in the presence of a radiolabeled bicarbonate tracer. The salinity of each microcosm incubation series is indicated. Results are presented as the average of triplicate samples taken from triplicate microcosms at each salinity with values from killed controls subtracted. Error bars represent the standard error of these assays. The microbialite mat samples were collected from a location where the salinity of the overlying water column was $15.6 \%$ and these are depicted as "Natural Salinity." Statistical significance of differences between measurements at each salinity and measurements at $15 \%$ salinity are denoted as $* * P<0.01$, ${ }^{*} P<0.1 ;$ ns, not significant with a $P>0.1$.

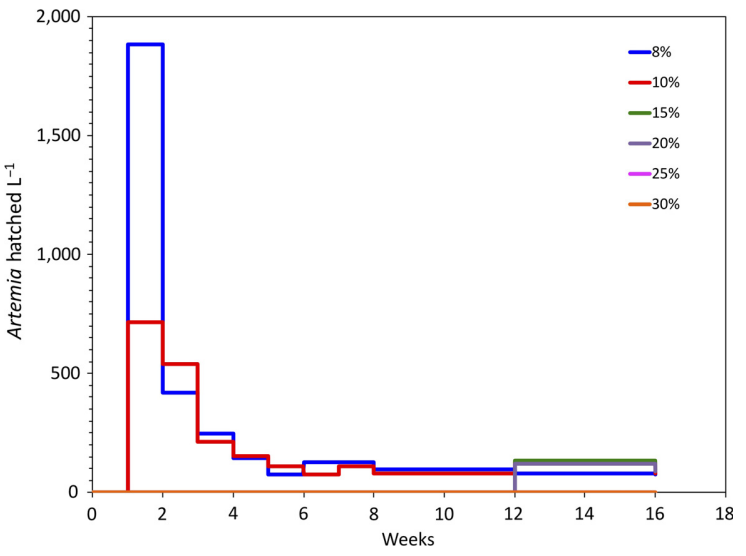

FIG. 6. Number of Artemia hatched from cysts and the number of individuals remaining in microcosms at different salinities, counted each week for 8 weeks total, and then again at 12 and 16 weeks. The percentages of Artemia hatched at both 25 and $30 \%$ salinity were 0 for all time points counted.

populations that were most susceptible to changes in salinity, in particular, how quantities of primary producers and their productivity are affected, which in turn could impact microbial heterotrophic consumers and higher trophic levels. Secondarily, we aimed to determine the salinity that maximized productivity and biomass production at both the level of primary producers and secondary consumers. This information was then used to predict the salinity where these ecosystem properties start to significantly decline and at what salinity decreases in primary productivity might be expected to impact higher trophic compartments.

Incubation of microbialite-associated mats at salinities lower than $15 \%$ resulted in net increases in 16S rRNA gene abundances, and incubation of mats at elevated salinity resulted in a decrease in 16S rRNA gene abundances (Fig. 4). The increase in gene abundances at lower salinities is likely due to a decrease in the stress imposed by salinity on populations comprising the mat (Oren 2006), even if they are halotolerant. For example, previous work conducted in the SA of GSL indicates that an artificial decrease in the native salinity from $\sim 11$ to $12 \%$ to $<5-6 \%$ stimulated sulfate reduction activity in benthic sediment-associated populations and resulted in the highest rates of growth of sulfate-reducing bacteria (Brandt et al. 2001). The dominant sulfate-reducing bacterium in the SA of GSL is related to Desulfobacterium (Desulfurobacterales), and transcripts associated with this genus were previously shown to be restricted to benthic sediments with salinities $<8 \%$ (Boyd et al. 2017). However, in our study, the abundance of sequences affiliated with the Desulfurobacterales decreased in all microcosm incubations, regardless of salinity (when normalized to quantities present at time 0; Fig. 3). This could be due to consumption of available sulfate in microcosm assays or due to a disruption of mat structure when microcosm assays were set up, which would likely 
result in less $\mathrm{O}_{2}$ consumption by heterotrophic bacteria that would otherwise protect anaerobic sulfate-reducers from toxic $\mathrm{O}_{2}$. The latter interpretation is consistent with a previous study conducted on hot spring mats, where a similar negative effect on the activity of sulfate reducers was observed when the mat community's physical structure was disturbed (Nishihara et al. 2018).

The dominant phototrophs in microcosm incubations were affiliated with the Chroococcales and Naviculales, and these exhibited different apparent sensitivities to salinity changes. For example, the abundance of the most dominant phototrophic order, Chroococcales, increased at both 10 and $20 \%$ salinity after 7 weeks of incubation, relative to abundances at $15 \%$ salinity. The increase in the abundance of sequences affiliated with the Chroococcales in microcosms incubated at 10\% salinity is consistent with a corresponding slight increase in the rate of $\mathrm{CO}_{2}$ fixation at this salinity and an increase in overall total biomass. Additionally, the optimal salinity for the growth of most Chroococcales cyanobacterial genera is reported to be between 5 and 15\% (GarciaPichel et al. 1998). Specifically, the dominant 16S rRNA gene sequence identified in mats from the SA of GSL were most closely related to a Euhalothece sp. that exhibits optimal growth at $\sim 11 \%$ salinity $(120 \mathrm{~g} / \mathrm{L}$; Mogany et al. 2018). This may suggest that the increases in $16 \mathrm{~S}$ rRNA gene abundance (both in total and for this order) and the similar rate of $\mathrm{CO}_{2}$ fixation in microcosms incubated at a decreased salinity of $10 \%$ when compared to $15 \%$ can be attributed to a shift to salinity conditions more conducive to the growth of this cyanobacterium. The presence of high densities of the secondary consumer Artemia could have top-down effects in these lower salinities, and this top-down effect could be muting the amounts of increased biomass observed.

Other anoxygenic phototrophic orders may also contribute to increases in the total number of $16 \mathrm{~S}$ rRNA genes and increased rates of $\mathrm{CO}_{2}$ fixation in microcosms incubated at decreased salinity relative to those incubated at $15 \%$. For example, the abundance of genes affiliated with Chromatiales increased at both 8 and $10 \%$ salinity when compared to $15 \%$ salinity. The primary Chromatiales sequence identified in GSL mats is related to Halochromatium salexigens ( $98 \%$ 16S rRNA gene identity), which grows optimally at salinities ranging from 8 to $11 \%$ (Kumar et al. 2007). As expected, the abundance of gene sequences affiliated with Chromatiales decreased in mats incubated at higher salinities. Likewise, the abundance of Rhodobacterales sequences affiliated with Roseovarius tolerans (100\% 16S rRNA gene identity) increased in mats incubated at lower salinities of $8-10 \%$, consistent with the optimal salinity for growth of this genus of 1.0-8.0\% (Labrenz et al. 1999).

Although optimal growth for Euhalothece strains is typically observed at salinities of $<15 \%$, they have been shown to tolerate salinities of up to $\sim 20-24 \%$, often with near-negligible effects on overall growth rate (GarciaPichel et al. 1998). Intriguingly, an increase in the abundance of sequences affiliated with the Euhalothece (Chroococcales) was observed in microcosms incubated at $20 \%$ salinity relative to $15 \%$ salinity. However, a corresponding increase in the rate of $\mathrm{CO}_{2}$ fixation and the abundance of total 16S rRNA genes was not observed. Rather, the rate of $\mathrm{CO}_{2}$ fixation and the abundance of total 16S rRNA genes decreased in microcosms incubated at $20 \%$. These decreases may be attributable to a decrease in sequences affiliated with the second most abundant phototroph, diatoms affiliated with Naviculales, and other phototrophic orders Chromatiales and Rhodobacterales (Fig. 3, Appendix S1: Fig. S1). Some diatoms within the order Naviculales are known to grow optimally at salinities up to $13 \%$, but most grow optimally at salinities of $<5 \%$ (Clavero et al. 2000). Although the optimal salinity for growth of the Naviculales population from the SA of GSL is not known, the increase in the abundance of sequences affiliated with this order at $10 \%$ salinity following 7 weeks' incubation (relative to the $15 \%$ salinity condition) suggests that it is lower than the salinity $(15.6 \%)$ of the SA at the time of sample collection.

The decrease in the abundance of $16 \mathrm{~S}$ rRNA genes at salinities of 25 and $30 \%$ was associated with a decrease in almost all orders, including a decrease in the abundance of all phototrophic lineages. These decreases are consistent with an overall decrease in primary production at the elevated salinities of 25 and $30 \%$, relative to $15 \%$ salinity. Phototrophs in GSL have been suggested to be maladapted to salinities $\geq 20 \%$ (Stephens 1990), although some species can maintain standing populations at such high salinities because of a lack of competition from other algae and a lack of predation (Brock 1975). The phototrophs identified in microbialite mats here and in previous studies (Lindsay et al. 2017) are inferred, based on phylogenetic associations, to grow optimally at salinities $<20 \%$ and their population numbers are thus expected to decline at salinities that exceed this threshold. It is possible, however, that communities subjected to increased salinity (e.g., $20 \%$ or more) could shift their species composition and recover over time and thereby may be more resilient to salinity shifts than indicated in the short-term (7-week) incubation experiments conducted here. For example, the decreased numbers of sequences affiliated with the phototrophic order Chroococcales at $20 \%$ salinity at 4 weeks of incubation recovered with an additional 3 weeks' incubation. Nonetheless, these data strongly suggest that an increase in the salinity to $>15 \%$ (i.e., $>20 \%$ ) will have a negative effect on the abundance of biomass and rates of $\mathrm{CO}_{2}$ fixation (primary productivity) due to maladaptation of these phototrophs to such conditions. Additionally, a lack of hatched Artemia likely indicates that decreases at these high salinities are not as extreme as they would be if grazing were occurring.

Secondary productivity was also negatively affected at higher salinities. Artemia cysts did not hatch at salinities of $\geq 25 \%$, which is likely due to the inhibitory effects on 
cyst hatching imposed by extreme hypersalinity on Artemia (Dana and Lenz 1986, Triantaphyllidis et al. 1995). Previous studies have shown that Artemia cysts fail to hatch at salinities of $>159 \mathrm{~g} / \mathrm{L} \quad(\sim 14.3 \%$ salinity $)$, although these data were determined for a different species of Artemia ( $A$. monica rather than A. franciscana) in Mono Lake, California, USA, and only monitored for a period of 14 days (Dana and Lenz 1986). Consistent with this previous work, we found that it took a total of 12 weeks before Artemia cysts hatched in microcosms with 15 or $20 \%$ salinity. It is possible that a longer incubation is needed to assess the hatch rate at higher salinities. After 16 weeks of incubation, all microcosms that supported hatching of Artemia had similar numbers of surviving individuals, indicating that amounts of microbial biomass present in either the benthic microbialite mat or planktonic phase at salinities ranging from 8 to $20 \%$ were capable of supporting the same finalized number of Artemia (Fig. 6).

The inability of Artemia to hatch at higher salinities (25 and 30\%) in this study can likely be attributed to the direct effects of salinity on the cysts; however, the survivability of Artemia after hatching at salinities from 8 to $20 \%$ could be due to either the physiological effects of high salinity or due to a change in the composition or the availability of food. Artemia from GSL have been shown to feed primarily and preferentially on photosynthetic biomass with a length/diameter of 4-8 $\mu \mathrm{m}$ (Makridis and Vadstein 1999). Thus, it is likely that the smaller-sized bacterial Euhalothece (Chroococcales) would be available for consumption, because the diameter of these cells ranges from 8 to $14 \mu \mathrm{m}$ (Mogany et al. 2018). In contrast, diatoms (Naviculales) range from 30 to over 100 $\mu \mathrm{m}$ in length by $7-21 \mu \mathrm{m}$ in width, a size that might make them unusable food sources. The survivability of Artemia in microcosms with salinities of up to $20 \%$ is thus consistent with the presence of an abundant Chroococcales population up to this salinity. It is also likely that the photosynthetic biomass present in the microbialite mat material was also present in the planktonic phase, as previous studies have shown that planktonic and periphyton communities also comprise Chroococcales and Naviculales populations (Lindsay et al. 2017).

The influence of salinity on the composition and abundance of primary and secondary consumers is of concern for the GSL ecosystem. As a shallow terminal lake with a large surface area, GSL is likely to be particularly susceptible to changes in climate or land use that can then affect lake level and lake surface area, and thus lake salinity. Recent models suggest that GSL could be highly impacted by changes in climate, including air temperature and precipitation when compared to other deeper lakes (Strong et al. 2014). In particular, it is likely that the salinity and temperature of GSL will change in response to predicted changes in climate (United States Global Change Research Program [USGCRP] 2009). For example, drought severity in the American
Southwest is predicted to increase for the next century (Cook et al. 2015) and if amounts of precipitation change or the temperature of GSL increases to levels predicted by conservative climate change models (Strong et al. 2014), salinities could increase to levels (i.e., $>20 \%$ ) that could become inhibitory to the primary producers identified in this study.

In addition to changes in climate predicted to occur over the next several decades (Cook et al. 2015), changes in water use primarily through diversions of streams, which have already resulted in substantial change to GSL with an overall reduction of flow into GSL by $40 \%$ and a decline in lake surface area by $50 \%$ since 1847 (Wurtsbaugh et al. 2017), will likely continue to impact GSL salinity, elevation, and surface area. Because microbialite "reefs" and associated mats are almost all located within $10 \mathrm{~km}$ of the shoreline and at shallow depths (Fig. 1), it is likely that a substantial decrease in surface area will expose these structures and that a major portion of primary producer communities will no longer persist. Indeed, arguably the largest and most abrupt modern change to the GSL ecosystem occurred in 1959 with the construction of the railroad causeway, which separated the NA and SA of the GSL and cut off the NA from most of the freshwater input to GSL (Stephens 1974). This caused significant changes resulting in salinities between 24.0 and $31.4 \%$, which has inhibited most of the key primary producers in microbialite communities and caused both microbialite biomass and Artemia biomass to decrease (Lindsay et al. 2017). These salinities are consistent with those determined in this study to be inhibitory to the abundant phototrophic taxa in SA microbialites, and inhibitory to Artemia hatch and survival.

The effects of increased salinity likely go beyond the ecological compartments that were examined in this study of GSL. In other locations, increased salinities or the disappearance of lake surface area have resulted in ecological, atmospheric, and economic impacts (Wurtsbaugh et al. 2017). For example, the desiccation of endorheic Lake Urmia in Iran has resulted in salinities that now exceed $350 \mathrm{~g} / \mathrm{L}$ ( $28.5 \%$ salinity), which eradicated the brine shrimp populations and led to the loss of apex species such as flamingos and other birds (Lotfi 2012, Stone 2015, Wurtsbaugh et al. 2017). Artemia populations cannot reproduce at high salinities because of osmotic stress, desiccation, or low oxygen tension, dependent on temperature (Browne and Wanigasekera 2000). At low salinities, Artemia reproduction is inhibited by predation or the sinking of cysts to the bottom of the lake, where the spring influx of fresh water in the top layers of the lake cannot induce hatching (Stephens 1990, Gajardo and Beardmore 2012). If GSL salinities are maintained at elevated concentrations over the thresholds measured in this study and in others $(\sim 20 \%$ salinity; Barnes and Wurtsbaugh 2015), the resultant lack of Artemia could result in major ecological consequences, as they support nearly 10 million migratory 
birds that use GSL as an important feeding ground annually (Vest and Conover 2011, Roberts 2013). Moreover, the aquaculture of brine shrimp cysts alone represents a total economic effect of 57 million dollars to this region (Great Salt Lake Advisory Council 2012) and this loss, combined with a loss of migratory bird stopovers, could significantly affect the local economy. This includes direct and indirect impacts on overall lake recreation and tourism, which rely on wildlife viewing and hunting, representing a total of 135.8 million dollars to the GSL economy (Great Salt Lake Advisory Council 2012).

\section{ConClusions}

Data presented here indicate that short-term increases in salinity to levels of $20 \%$ or greater negatively impact the abundance of periphyton microbialite mat communities and alter their composition. This negative affect was particularly acute for abundances of the dominant primary producers, including the cyanobacterium Euhalothece and the diatom Navicula. The negative effect of increasing salinity to levels exceeding $20 \%$ on the abundance of these phototrophic organisms is further reflected in significant decreases in the primary productivity of these communities. The decrease in available biomass at elevated salinities exceeding 20\% combined with physiological stress imposed by hypersalinity negatively impacts the hatching and survivability of the secondary consumer Artemia, which may feed and depend on benthic mats. The abundance of microbial 16S rRNA genes (a proxy for microbial biomass), in particular those associated with Euhalothece and Navicula, and the rates of DIC uptake were highest at a salinity in the range of 10 $15 \%$, suggesting that this is the optimal salinity range for the functioning of this ecological compartment. The number of Artemia cysts that hatched and survived were also high in microcosms incubated at $10 \%$, but were significantly decreased at $15 \%$ salinity. This further indicates that salinities of $<15 \%$ promote maximal Artemia hatching in GSL. Additional work is needed to improve the understanding of how communities that start at salinities other than $15 \%$ (e.g., mats sampled at 10 or $20 \%$ salinity) might change in response to increased and decreased salinity and what effect this would have on primary and secondary production in the GSL ecosystem.

Over the past several hundred years, GSL has undergone short-term increases in salinity due to natural- (i.e., climate change) and anthropogenic- (i.e., diversion of rivers, construction of causeways) influenced reasons, including increases to salinities in the SA of the lake to over $20 \%$ (Baxter 2018). Long-term exposure to increased salinity in the NA post causeway construction has resulted in drastic restructuring of microbialite associated mat communities, including a near complete loss of primary producers (i.e., Euhalothece and Navicula) and a significant decrease in Artemia population abundances (Lindsay et al. 2017). Even the recent breach in the causeway has not been able to provide significantly more water exchange between the two arms of the lake, and the NA and SA salinities remain divergent (Larsen 2018). The sensitivity of GSL to changes in climate (evaporation) and diversions of water (freshwater inputs) suggests that future changes in the salinity are likely. Collectively, the data presented here indicate that a continued and sustained increase in the salinity of GSL due to climate change or land- and water-use decisions to levels that exceed $20 \%$ will have a negative impact on the productivity of the lake, which could in turn initiate a negative cascading effect on the productivity of higher trophic levels, including Artemia and migratory birds that depend on these ecological compartments. However, because of the apparent resilience of the dominant phototroph (Euhalothece) to short-term increases in salinity, ephemeral changes in the salinity of GSL might be tolerated and ecological tipping points might be avoided.

\section{ACKNOWLEDGMENTS}

This work was supported by the Doyle W. Stephens scholarship from Friends of Great Salt Lake and by support from the National Aeronautics and Space Administration Earth and Space Science Fellowship Program (NNX16AP51H) to M. R. Lindsay. R. E. Johnston was supported by the Montana State University (MSU) Undergraduate Scholars Program, funded by the MSU Office of the Provost.

\section{Literature Cited}

Aldrich, T. W., and D. S. Paul. 2002. Avian ecology of Great Salt Lake. Pages 343-374 in J. W. Gwynn, editor. Great Salt Lake: an overview of change. Utah Department of Natural Resources and Utah Geological Survey Special Publication, Salt Lake City, Utah, USA.

An, S. M., J. H. Noh, H. R. Lee, D. H. Choi, J. H. Lee, and E. C. Yang. 2016. Complete mitochondrial genome of biraphid benthic diatom, Navicula ramosissima (Naviculales, Bacillariophyceae). Mitochondrial DNA Part B 1:549-550.

Barnes, B. D., and W. A. Wurtsbaugh. 2015. The effects of salinity on plankton and benthic communities in the Great Salt Lake, Utah, USA: a microcosm experiment. Canadian Journal of Fisheries and Aquatic Sciences 72:807-817.

Baskin, R. 2014. Occurrence and spatial distribution of microbial bioherms in Great Salt Lake, Utah. Dissertation. University of Utah, Salt Lake City, Utah, USA.

Baxter, B. K. 2018. Great Salt Lake microbiology: a historical perspective. International Microbiology 21:79-95.

Belovsky, G. E., et al. 2011. The Great Salt Lake Ecosystem (Utah, USA): long term data and a structural equation approach. Ecosphere 2:1-40.

Ben Hania, W., M. Joseph, P. Schumann, B. Bunk, A. Fiebeg, C. Spröer, H. P. Klenk, M. L. Fardeau, and S. Spring. 2015. Complete genome sequence and description of Salinispira pacifica gen. nov., sp. nov., a novel spirochaeta isolated from a hypersaline microbial mat. Standards in Genomic Sciences. https://doi.org/10.1186/1944-3277-10-7

Boyd, E. S., W. D. Leavitt, and G. G. Geesey. 2009. $\mathrm{CO}_{2}$ uptake and fixation by a thermoacidophilic microbial community attached to precipitated sulfur in a geothermal spring. Applied and Environmental Microbiology 75:4289-4296.

Boyd, E. S., R. K. Lange, A. C. Mitchell, J. R. Havig, M. J. Lafreniere, T. L. Hamilton, E. L. Shock, J. W. Peters, and M. L. Skidmore. 2011. Diversity, abundance, and potential 
activity of nitrifying and nitrate-reducing microbial assemblages in a subglacial ecosystem. Applied and Environmental Microbiology 77:4778-4787.

Boyd, E. S., K. M. Fecteau, J. R. Havig, E. L. Shock, and J. W. Peters. 2012. Modeling the habitat range of phototrophs in Yellowstone National Park: toward the development of a comprehensive fitness landscape. Frontiers in Microbiology 3:221.

Boyd, E. S., R. Yu, T. Barkay, T. L. Hamilton, B. K. Baxter, D. L. Naftz, and M. Marvin-DiPasquale. 2017. Effect of salinity on mercury methylating benthic microbes and their activities in Great Salt Lake, Utah. Science of the Total Environment 581:495-506.

Brandt, K. K., F. Vester, A. N. Jensen, and K. Ingvorsen. 2001. Sulfate reduction dynamics and enumeration of sulfate-reducing bacteria in hypersaline sediments of the Great Salt Lake (Utah, USA). Microbial Ecology 41:1-11.

Brock, T. D. 1975. Salinity and the ecology of Dunaliella from Great Salt Lake. Journal of General Microbiology 89:285292.

Browne, R. A., and G. Wanigasekera. 2000. Combined effects of salinity and temperature on survival and reproduction of five species of Artemia. Journal of Experimental Marine Biology and Ecology 244:29-44.

Cannon, J. S., and M. A. Cannon. 2002. The Southern Pacific railroad trestle - past and present. Pages 283-294 in J. W. Gwynn, editor. Great Salt Lake, an overview of change. Special Publication of the Utah Department of Natural Resources, Salt Lake City, Utah, USA.

Chidsey, T. C. J., M. D. Vanden Berg, and D. E. Eby. 2015. Petrography and characterization of microbial carbonates and associated facies from modern Great Salt Lake and Uinta Basin's Eocene Green River Formation in Utah, USA. Microbial Carbonates in Space and Time: Implications for Global Exploration and Production 418:261-286.

Clavero, E., M. Hernández-Mariné, J. O. Grimalt, and F. Garcia-Pichel. 2000. Salinity tolerance of diatoms from thalassic hypersaline environments. Journal of Phycology 36:10211034.

Collins, N. 1979. Population ecology of Ephydra cineria jones (Diptera: Ephydridae), the only benthic metazoan of the Great Salt Lake, U.S.A. Hydrobiologia 69:99-112.

Colman, D. R., J. Feyhl-Buska, K. J. Robinson, K. M. Fecteau, H. Xu, E. L. Shock, and E. S. Boyd. 2016. Ecological differentiation in planktonic and sediment-associated chemotrophic microbial populations in Yellowstone hot springs. FEMS Microbiology Ecology. https://doi.org/10.1093/fem sec/fiw137

Cook, B. I., T. R. Ault, and J. E. Smerdon. 2015. Unprecedented 21st century drought risk in the American Southwest and Central Plains. Science Advances 1:e1400082.

Dana, G. L., and P. H. Lenz. 1986. Effects of increasing salinity on an Artemia population from Mono Lake, California. Oecologia 68:428-436.

Dowd, S. E., Y. Sun, P. R. Secor, D. D. Rhoads, B. M. Wolcott, G. A. James, and R. D. Wolcott. 2008. Survey of bacterial diversity in chronic wounds using pyrosequencing, DGGE, and full ribosome shotgun sequencing. BMC Microbiology 8:1-15.

Eardley, A. J. 1938. Sediments of Great Salt Lake, Utah. AAPG Bulletin 22:1305-1411.

Edgar, R. C., B. J. Haas, J. C. Clemente, C. Quince, and R. Knight. 2011. UCHIME improves sensitivity and speed of chimera detection. Bioinformatics 27:2194-2200.

Gajardo, G. M., and J. A. Beardmore. 2012. The brine shrimp Artemia: adapted to critical life conditions. Frontiers in Physiology $3: 1-8$.
Garcia-Pichel, F., U. Nübel, and G. Muyzer. 1998. The phylogeny of unicellular, extremely halotolerant cyanobacteria. Archives of Microbiology 169:469-482.

Great Salt Lake Advisory Council. 2012. Economic significance of the Great Salt Lake to the State of Utah. Bioeconomics, Missoula, Montana, USA.

Hamilton, T. L., J. W. Peters, M. L. Skidmore, and E. S. Boyd. 2013. Molecular evidence for an active endogenous microbiome beneath glacial ice. ISME Journal 7:1402-1412.

Hassibe, W. R., and W. G. Keck. 1991. The Great Salt Lake. Pages 25 in U. G. Survey, editor. United States Government Printing Office. Reston, Virginia, USA.

Jones, B. F., D. L. Naftz, R. J. Spencer, and C. G. Oviatt. 2009. Geochemical evolution of Great Salt Lake, Utah, USA. Aquatic Geochemistry 15:95-121.

Kumar, P. A., T. N. R. Srinivas, C. Sasikala, and C. V. Ramana. 2007. Halochromatium roseum sp. nov., a non-motile phototrophic gammaproteobacterium with gas vesicles, and emended description of the genus Halochromatium. International Journal of Systematic and Evolutionary Microbiology 57:2110-2113.

Labrenz, M., M. D. Collins, P. A. Lawson, B. J. Tindall, P. Schumann, and P. Hirsch. 1999. Roseovarius tolerans gen. nov., sp. nov., a budding bacterium with variable bacteriochlorophyll $a$ production from hypersaline Ekho Lake. International Journal of Systematic Bacteriology 49:137-147.

Larsen, L. 2018. 1 year after the breach, Great Salt Lake causeway creates mixed feelings. Standard-Examiner, Ogden, UT. 22 January2018. https://www.standard.net/news/environment/ year-after-the-breach-great-salt-lake-causeway-creates-mixed/ article_c7e0d88f-3748-51d4-b177-79ec136ee88b.html

Lindeman, R. L. 1942. The trophic-dynamic aspect of ecology. Ecology 23:399-417.

Lindsay, M. R., et al. 2017. Microbialite response to an anthropogenic salinity gradient in Great Salt Lake, Utah. Geobiology 15:131-145.

Lindsay, M. R., M. J. Amenabar, K. M. Fecteau, R. V. Debes, M. C. Fernandes, K. E. Fristad, H. Xu, T. M. Hoehler, E. L. Shock, and E. S. Boyd. 2018. Subsurface processes influence oxidant availability and chemoautotrophic hydrogen metabolism in Yellowstone hot springs. Geobiology 6:674692.

Lotfi, A. 2012. Lake Uromiyeh: a concise baseline report. Impel Review Initiative, Department of Environment, United Nations Development Program, New York, New York, USA.

Madison, R. J. 1970. Effects of a causeway on the chemistry of the brine in Great Salt Lake, Utah. Water-Resources Bulletin 14. U.S. Geological Survey, Washington, D.C., USA.

Makridis, P., and O. Vadstein. 1999. Food size selectivity of Artemia franciscana at three developmental stages. Journal of Plankton Research 21:2191-2201.

Mogany, T., F. M. Swalaha, M. Allam, P. S. Mtshali, A. Ismail, S. Kurami, and F. Bux. 2018. Phenotypic and genotypic characterisation of an unique indigenous hypersaline unicellular cyanobacterium, Euhalothece sp. nov. Microbiological Research 211:47-56.

Naftz, D. L., F. J. Millero, B. F. Jones, and W. R. Green. 2011. An equation of state for hypersaline water in Great Salt Lake, Utah, USA. Aquatic Geochemistry 17:809-820.

Nishihara, A., S. Haruta, S. E. McGlynn, V. Thiel, and K. Matsuura. 2018. Nitrogen fixation in thermophilic chemosynthetic microbial communities depending on hydrogen, sulfate, and carbon dioxide. Microbes and Environments 33:10-18.

Oren, A. 2006. Life at high salt concentrations. Prokaryotes 2:263-282.

Oren, A. 2013. Life at high salt concentrations. Pages 421-440 in $\mathrm{E}$. Rosenberg, editor. The prokaryotes. Springer, Berlin, Germany. 
Paine, R. T. 1980. Food webs: linkage, interaction strength and community infrastructure. Journal of Animal Ecology 49:666-685.

Rabus, R., R. Nordhaus, W. Ludwig, and R. Widdel. 1993. Complete oxidation of toluene under strictly anoxic conditions by a new sulfate-reducing bacterium. Applied and Environmental Microbiology 59:1444-1451.

Ripple, W. J., J. A. Estes, O. J. Schmitz, V. Constant, M. J. Kaylor, A. Lenz, J. L. Motley, K. E. Self, D. S. Taylor, and C. Wolf. 2016. What is a trophic cascade? Trends in Ecology and Evolution 31:842-849.

Roberts, A. J. 2013. Avian diets in a saline ecosystem: Great Salt Lake, Utah, USA. Human-Wildlife Interactions 7:158-168.

Schloss, P. D., et al. 2009. Introducing mothur: open-source, platform-independent, community-supported software for describing and comparing microbial communities. Applied and Environmental Microbiology 75:7537-7541.

Stephens, D. W. 1974. A summary of biological investigations concerning the Great Salt Lake, Utah (1861-1973). Great Basin Naturalist 34:221-229.

Stephens, D. W. 1990. Changes in lake levels, salinity and the biological community of Great Salt Lake (Utah, USA), 1847 1987. Hydrobiologia 197:139-146.

Stephens, D. W. 1998. Salinity-induced changes in the aquatic ecosystem of Great Salt Lake, Utah. Pages 1-7 in J. Pitman and A. Carroll, editors. Modern and ancient lake systems, Utah Geological Survey Guidebook 26. Utah Geological Survey, Salt Lake City, Utah, USA.

Stone, R. 2015. Saving Iran's great salt lake. Science 349:1044 1047.

Strong, C., A. K. Kochanski, and E. T. Crosman. 2014. A slab model of the Great Salt Lake for regional climate simulation. Journal of Advances in Modeling Earth Systems 6:602-615.

Tarboton, D. 2017. Great Salt Lake Bathymetry. Hydroshare. http://www.hydroshare.org/resource/582060f00f6b443bb26e 896426d9f62a

Terborgh, J., K. Feeley, M. Silman, P. Nuñez, and B. Balukjian. 2006. Vegetation dynamics of predator-free land-bridge islands. Journal of Ecology 94:253-263.

Thompson, R. M., et al. 2012. Food webs: reconciling the structure and function of biodiversity. Trends in Ecology and Evolution 27:689-697.

Triantaphyllidis, G. V., K. Poulopoulou, T. J. Abatzopoulos, C. A. P. Perez, and P. Sorgeloos. 1995. International study on Artemia XLIX. Salinity effects on survival, maturity, growth, biometrics, reproductive and lifespan characteristics of a bisexual and a parthenogenetic population of Artemia. Hydrobiologia 302:215-227. University of British Columbia.
2012. Navicula spp. In: Phyto'pedia-The Phytoplankton Encyclopaedia Project. Department of Earth, Ocean and Atmospheric Sciences, The University of British Columbia, British Columbia, Canada.

Urschel, M. R., M. R. Kubo, T. M. Hoehler, J. W. Peters, and E. S. Boyd. 2015. Carbon source preference in chemosynthetic hot spring communities. Applied and Environmental Microbiology 81:3834-3847.

United States Global Change Research Program [USGCRP]. 2009. Global climate change impacts in the United States. USGCRP, New York, New York, USA.

Vadeboncoeur, Y., E. Jeppesen, M. J. Vander Zanden, H. Schierup, K. Christoffersen, and D. M. Lodge. 2003. From Greenland to green lakes: cultural eutrophication and the loss of benthic pathways in lakes. Limnology and Oceanography 48:1408-1418.

Vest, J. L., and M. R. Conover. 2011. Food habits of wintering waterfowl on the GSL, Utah. Waterbirds 34:40-50.

Wang, Q., G. M. Garrity, J. M. Tiedje, and J. R. Cole. 2007. Naive Bayesian classifier for rapid assignment of rRNA sequences into the new bacterial taxonomy. Applied and Environmental Microbiology 73:5261-5267.

Western Hemisphere Shorebird Reserve Network [WHSRN]. 2018. Great Salt Lake. in W. H. S. R. Network, editor. https:// www.whsrn.org/great-salt-lake

Wotipka, S. 2014. Brine shrimp by the billions in the Great Salt Lake. High Country News. 11 June 2014. https://www.hen.or g/issues/46.10/brine-shrimp-by-the-billions-in-the-great-saltlake

Wurtsbaugh, W. A. 1992. Food-web modification by an invertebrate predator in the Great Salt Lake (USA). Oecologia 89:168-175.

Wurtsbaugh, W. A. 2009. Biostromes, brine flies, birds and the bioaccumulation of selenium in Great Salt Lake, Utah. Natural Resources \& Environment 15:1-15.

Wurtsbaugh, W. A., J. Gardberg, and C. Izdepski. 2011. Biostrome communities and mercury and selenium bioaccumulation in the Great Salt Lake (Utah, USA). Science of the Total Environment 409:4425-4434.

Wurtsbaugh, W. A., C. Miller, S. E. Null, R. J. DeRose, P. Wilcock, M. Hahnenberger, F. Howe, and J. Moore. 2017. Decline of the world's saline lakes. Nature Geoscience $10: 816-821$

Xia, J., C. A. Dunlap, L. Flor-Weiler, A. P. Rooney, G. J. Chen, and Z. J. Du. 2016. Longibacter salinarum gen. nov., sp. nov., isolated from a marine solar saltern. International Journal of Systematic and Evolutionary Microbiology $66: 3287-3292$.

\section{SUPPORTING INFORMATION}

Additional supporting information may be found in the online version of this article at http://onlinelibrary.wiley.com/doi/10. 1002/ecy.2611/suppinfo

\section{Data Availability}

Data available from the National Center for Biotechnology Information Short Read Archive under BioProject number PRJNA492463. 